\title{
Communication
}

\section{A Multidisciplinary Research Agenda for Understanding Vaccine-Related Decisions}

\author{
Heidi Larson ${ }^{1}$, Julie Leask ${ }^{2, *}$, Sian Aggett ${ }^{3}$, Nick Sevdalis ${ }^{4}$ and Angus Thomson ${ }^{5}$ \\ 1 London School of Hygiene \& Tropical Medicine, London WC1 7HT, UK; \\ E-Mail: heidi.larson@1shtm.ac.uk
}

2 School of Public Health, University of Sydney, Sydney NSW 2006, Australia

3 International Engagement Project Manager, The Wellcome Trust, London NW1 2BE, UK;

E-Mail: s.aggett@wellcome.ac.uk

4 Center for Patient Safety and Service Quality and Department of Surgery and Cancer, Imperial College

London, London W21 PG, UK; E-Mail: n.sevdalis@imperial.ac.uk

5 Vaccination Advocacy, Sanofi Pasteur, Lyon 69007, France;

E-Mail: angus.thomson@sanofipasteur.com

* Author to whom correspondence should be addressed; E-Mail: julie.leask@sydney.edu.au.

Received: 9 June 2013; in revised form: 21 June 2013 / Accepted: 2 July 2013 /

Published: 18 July 2013

\begin{abstract}
There is increasingly broad global recognition of the need to better understand determinants of vaccine acceptance. Fifteen social science, communication, health, and medical professionals (the "Motors of Trust in Vaccination" (MOTIV) think tank) explored factors relating to vaccination decision-making as a step to building a multidisciplinary research agenda. One hundred and forty seven factors impacting decisions made by consumers, professionals, and policy makers on vaccine acceptance, delay, or refusal were identified and grouped into three major categories: cognition and decision-making; groups and social norms; and communication and engagement. These factors should help frame a multidisciplinary research agenda to build an evidence base on the determinants of vaccine acceptance to inform the development of interventions and vaccination policies.
\end{abstract}

Keywords: vaccination; policy; communication; attitudes 


\section{Introduction}

Immunization has saved millions of lives worldwide since the introduction of the first vaccine more than 200 years ago. However, the sustained success of immunization programs, a cornerstone of public health, is challenged by increasing vaccine questioning, hesitancy, and refusals. These occur for a range of reasons varying from religious and philosophical to concerns about vaccine safety and schedules, or questions about the relevance of some vaccines [1,2]. Moreover, for each vaccine and its target disease(s) there is a unique set of interested "publics" with different positive and negative perceptions and attitudes to vaccination. High profile vaccine scares have brought significant disruption or cessation to entire vaccine programs. For example, despite Andrew Wakefield's 1998 article in The Lancet [3] being refuted, retracted, and declared fraudulent [4], uptake of measles, mumps and rubella (MMR) vaccination dipped in the UK from $91 \%$ in 1998 to $80 \%$ by 2004 [5]. There have since been several outbreaks of measles and, 14 years after the local transmission of measles was halted in the UK, the disease was once again reported to be endemic in 2008 [6], and the beginning of 2013 saw the highest rates of measles in two decades. In both 2010 and 2011, there were over 30,000 cases annually of measles in the European region [7]. In another instance, in 2003 five states in Northern Nigeria ordered the boycott of the oral polio vaccine (OPV), alleging that the vaccines were contaminated with anti-fertility substances in a plot by Western governments to reduce the Muslim population [8]. As a result of the boycott, polio reappeared in more than 15 formerly polio-free African countries (and as far afield as Indonesia) [9], and challenges to eradication persist [10]. A more recent example of widespread vaccine refusals was during the 2009-2010 response to the (A)H1N1 pandemic threats, during which populations, including health professionals, around the world had dismally low acceptance of the Influenza A (H1N1) vaccine for a complex mix of reasons from perception of low-to-no disease risk, suspicions around the motives of government and the pharmaceutical industry, and historic memories of reports of an earlier swine flu vaccine causing Guillain-Barré syndrome (GBS). These examples highlight the complex social, historical, political, and power dimensions that influence vaccination uptake [1].

These experiences and the research on drivers of vaccination behavior have shown that vaccination decision-making is driven by different factors according to individual or group experiences and contexts, beliefs, and knowledge. Dependent on the viewpoint of the public/s, healthcare professional or government/healthcare system, the spectrum of attitudes toward vaccines ranges from considering them to be life-saving, to viewing them as a danger to health. Research also demonstrates that facts only go so far in determining decision-making; cognitive heuristics are equally important drivers. For example, the regret that people associate with potential adverse events after MMR vaccination has been shown to be a key predictor of MMR uptake [11]. Other studies have shown that many factors that affect behavior are unrelated to facts or awareness, and that traditional modes of health education that are more message-driven rather than dialog-promoting, may have only a small impact on behavior [12,13]. A recent systematic review of the evidence for effective national immunization schedule promotional communications found no evidence that improved knowledge led to increased childhood vaccine uptake, or even intention to vaccinate [14].

To date, much of the literature on vaccination decision-making has identified attitudinal and demographic correlates of complete and incomplete vaccine uptake largely in individuals. The published 
research has mostly been uni-disciplinary-i.e., drawing from a single specialty (like psychology, or sociology, or public health). While important, the field needs to draw from a range of rich theoretical understandings in other areas of health that can inform more holistic frameworks to understand vaccine decisions and their motivations. Multi-disciplinary approaches to understanding vaccination behavior could also further extend the evidence base, making the most of the tools and frameworks available within the different disciplines. Finally, further development of the field will require the design and evaluation of theory, and evidence-informed interventions at an individual, community, and national level to address the identified influences of vaccination decisions.

This paper reports on a two-day workshop with a multidisciplinary group of experts aimed at mapping, firstly, the known and potential drivers and barriers to vaccination at the individual and societal level, and, secondly, a research framework that allows future research to address them. Our ultimate aim was to inform a new research agenda from a rich multidisciplinary evidence base to inform vaccination program design and policy making.

\section{Methods}

In December 2010, an international think tank called "MOTIV" (Motors of Trust in Vaccination) was convened in London. The think tank deliberately assembled professionals with diverse expertise both within, and beyond, vaccinology. The 15 participants were variously expert in medical science, vaccinology, epidemiology, pediatrics, immunization policy and programs, immunization behavior, global health, psychology, anthropology, sociology, decision science, communication science, advocacy, public engagement, and manufacturing. The specific aim was to map the complex web of factors that may influence decision-making about vaccines at all levels, including individuals, peer groups, clinicians, and policy makers.

These aims were addressed through a range of interactive sessions. First, a structured brainstorm was carried out where members were asked to spontaneously identify factors affecting vaccination-related behavior - including vaccine acceptance, hesitancy, and refusal-by consumers, professionals, and policy makers. This involved the use of a "reverse brainstorm" technique to help participants look at issues around vaccination uptake "through new eyes". Here, participants were asked to consider the issue of vaccination from the opposition point of view - and think of ways to make uptake of a vaccine program as poor as possible (in this case a fictitious new vaccine with data from clinical trials showing acceptable levels of safety and efficacy).

Following the reverse brainstorm, participants identified factors/determinants of vaccine decisionmaking. The ideas were captured in an iterative manner and clustered by MOTIV participants into three major domains. Participants were then assigned to three teams that would each explore one of the major domains. Each team reviewed the list of factors/determinants in their assigned domain and then ranked them based on their expert perceptions according to importance, level of evidence, feasibility/actionability, and the need for more research. These key factors/determinants were distilled into research questions that could be taken forward for further investigation. Key factors/determinants for which a research framework could be developed were finally identified and discussed within the entire MOTIV group. 


\section{Results}

The brainstorming identified poor communication, safety concerns, political issues, anti-vaccination activism, and animal rights as the major areas under which a vaccine program might be derailed.

Regarding determinants of vaccination decision-making, the MOTIV expert group identified 61 factors that may affect vaccination-related behavior in consumers, professionals and policy makers (Appendix 1). These factors were further iteratively organized into "clusters", which were grouped under three major domains: cognition and decision-making; groups and social norms; and communications and engagement.

Research questions for further investigation were derived across the three major domains of influence on vaccination uptake, as detailed below. Boxes 1 and 2 illustrate two exemplars of such research questions.

Box 1. Which cognitive processes mediate vaccine decision-making and what are their relative roles in different contexts?

A range of cognitions influence vaccination decision-making, including heuristics. These are cognitive shortcuts used for making decisions about risk. One well-described heuristic in vaccination decisions is omission bias. This bias occurs if poor outcomes arising from an "action" (e.g., a reaction to a vaccine arising from deliberate acceptance of a vaccine) are viewed more unfavorably than poor outcomes arising from an "inaction" (e.g., disease contraction arising from "taking a chance with fate"), even if those outcomes are objectively identical, or omission is in fact more risky. Psychologically, omission bias has been linked to the emotion of regret: decision-makers tend to experience more regret for an outcome that they perceive as a consequence of their own voluntary "action" than for the very same outcome if that is perceived to be a consequence of luck or fate. Within the context of immunization, typically immunizing is seen as a conscious "action" whereas not immunizing (i.e., "doing nothing") is seen as "inaction". Evidence for omission bias has been demonstrated in relation to pertussis [11,12], MMR [13] and H1N1 vaccines [14].

Following the identification of drivers and barriers to vaccination and the related decision making processes, we sought to outline a viable research framework. Figure 1 presents an overarching framework aimed at outlining and systematizing a multidisciplinary research approach that is directly linked to evidence-based policy making. The framework is grounded on the types of themes that emerged through the expert brainstorming-namely the cognitive, social/interpersonal, and communication-related influences on attitudes to immunization and vaccination decision-making. A four-step iterative cycle is described. In the first step, descriptive and experimental research offers scientific definitions and illustrations of the issues to be tackled (e.g., omission bias in immunization decisions). In the second step, the findings are translated into interventions-typically including individual decision-makers (e.g., a de-biasing technique to be applied by community nurses or physicians offering vaccinations), the wider public, and also healthcare professionals. In the third step, these interventions are prospectively evaluated for effectiveness and the findings are fed back into the evidence base in the fourth and final step. 
Box 2. How does engagement with the various publics influence the level of trust in vaccines, vaccinations and vaccination-promoting groups or organizations?

Which public engagement strategies within the areas of vaccination decision-making and broader healthcare have achieved their goals, and how and why have they achieved their goals? How does/should communication and engagement change according to culture, geographical region or broadcast channel?

Public engagement is an umbrella term for a range of activities that occur at the interface between the specialist and non-specialist. Engagement is defined more by its ethos than by the vehicles of engagement. A key consideration is power: who is driving an engagement process, who owns the conversation, and how far can this process meet different stakeholders' multiple agendas? The emphasis of engagement is not to get public buy-in for a health program or technology; it is something more collaborative than lobbying or campaigning and goes beyond health promotion. Engagement aims to catalyze a two-way interaction, and well-executed public engagement will ultimately enable more critically aware, insightful decisions for all parties. This may be breaking new and difficult ground for many professionals and scientists and is therefore an important area for future research.

Figure 1. A dynamic multidisciplinary research framework to drive evidence-based policy making in vaccination.

I-Problem definition

Mapping, segmenting, weighting of

known vaccination drivers, barriers \& influences on decision-making
IV-Review \& refinement

Increased understanding and revised research and development programs

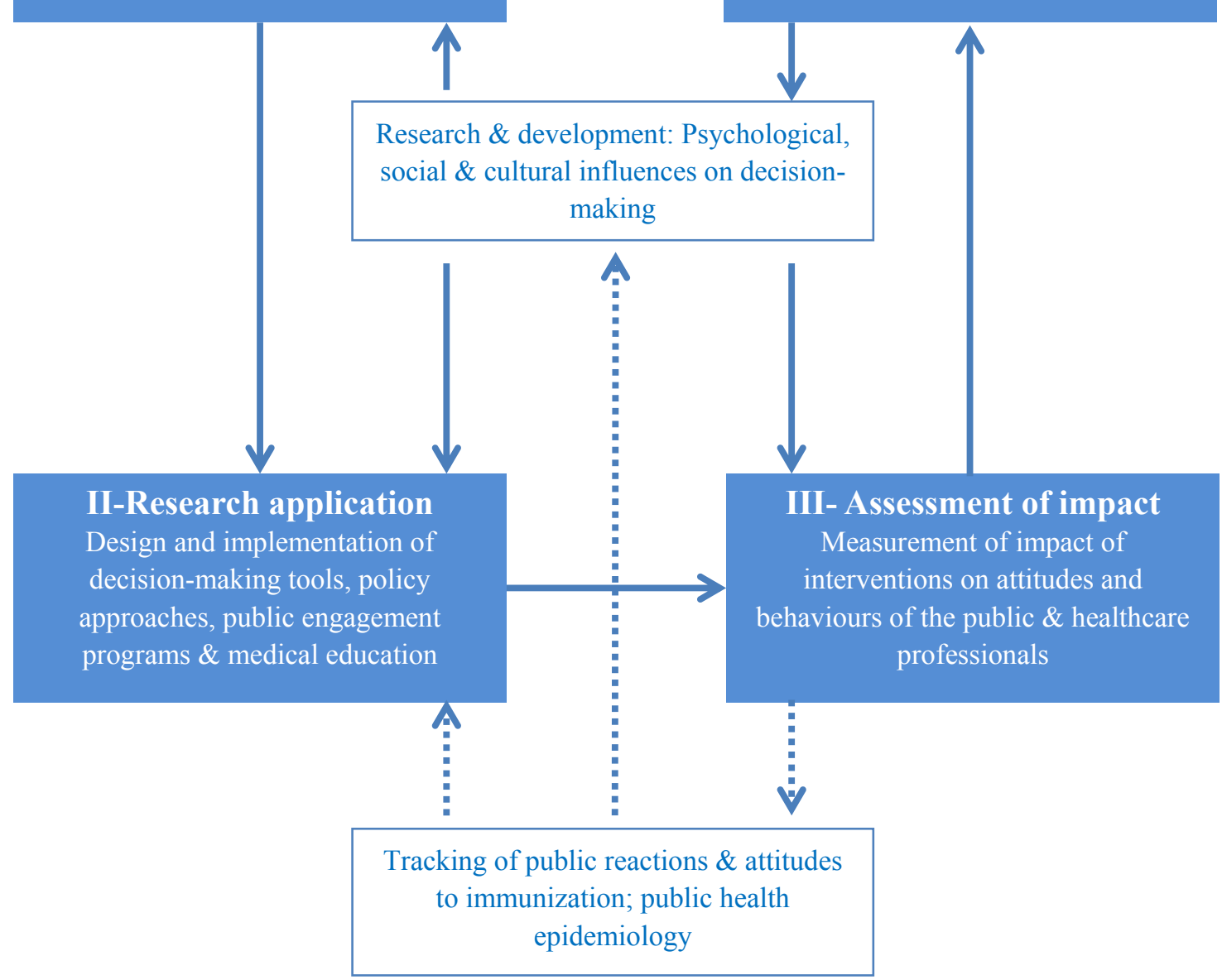


Importantly, the framework rests on robust multidisciplinary research and development processwhich includes key social and behavioral sciences. It also identifies the need for real-life longitudinal tracking not only of coverage and disease outbreaks via epidemiological methods, but also of behavioral and social reactions to immunization. The latter are aimed as explanations for and predictors of the former.

The basic premise of the framework is a dynamic approach to the generation and evaluation of new evidence to drive policy-making and program design. Vaccine decision-making is recognized here as a dynamic field of enquiry that can be rapidly affected by new vaccine developments, novel social movements (e.g., newly emerging social networks) and the increasing quest for evidence-based policy. The iterative link described here between multidisciplinary science and real-life coverage/attitudes to vaccines allows this framework to offer insights into policy making.

\section{Discussion}

The MOTIV workshop brought together a multidisciplinary group of experts and aimed at mapping drivers and barriers to vaccination to inform future research priorities. The ultimate aim of the workshop was to contribute to a contemporary research agenda, which will in turn inform vaccination policy-making and program design (in the manner outlined in Figure 1). It is clear from the factors identified that public engagement around vaccines needs to be broad and multifactorial, with engagement at multiple levels. These include policy-making (e.g., deliberative democracy), program design (including delivery) and the development of risk communication strategies.

Methodological improvements are required for better understanding of vaccine decision-making across populations and contexts and over time. Self-reported vaccine uptake and cross-sectional studies (where we assume causation between a certain attitude and behavior from measurements made only at one time point) limit the robustness of research into vaccination decision-making. In this context, attention to improving research design and data quality is essential, to provide a clear understanding of the relative contribution of factors such as trust, risk perception, online networks, peer networks, and misinformation.

Theoretically sound research frameworks and validated methods are also important. Use of recent, robust evidence-based attitude measurement instruments to evaluate the predictors of MMR uptake clearly shows that differences exist in the way vaccine-acceptors and vaccine-decliners think about several key factors regarding vaccination and disease control [15].

The MOTIV approach has some limitations. The faculty consisted of experts across diverse fields but did not exhaust the range of potentially relevant areas of expertise. Moreover, during the group sessions it was agreed that the domain "Communication" is too broad an area and more specific research topics need to be defined within the broader realm of communication. Additionally there was a significant degree of crossover between the domains - for example "Trust" overlaps with "Public engagement". The question of "What influences policy decision-making?" was identified as missing and was subsequently added to the decision-making category. Further, no formal consensus building methods were applied, as the idea-generation techniques used throughout the workshop were solely qualitative.

These limitations notwithstanding, we take the view that the questions outlined, and the proposed framework, are timely. Recent global events have demonstrated a desire for strategic attention to 
vaccine decision-making. The need to strengthen public support for vaccination efforts is one of the four components that comprise the Global Vaccine Action Plan, endorsed by the World Health Assembly (2012), and catalyzed by the Decade of Vaccines collaboration [13]. Additionally, WHO Strategic Group of Experts (SAGE) on immunization created a working group to specifically address vaccination hesitancy in 2012.

Just as vaccine development and testing is informed by science and research, so must our understanding of vaccine decision-making by publics, professionals, and policy makers be informed by robust scientific methods. This understanding will more credibly inform appropriate interventions to support decision-making. This framework provides the groundwork for a more explicitly articulated research agenda on vaccine decision-making. It suggests cross-disciplinary investigations (e.g., applying social networking theories to understanding community influence) and provides a starting point for researchers to identify areas well understood and those needing further enquiry.

An approach to researching vaccine decision-making and to translating the research findings into usable building blocks for policy making has been described, involving a range of multidisciplinary factors that cannot be addressed simply with existing health metrics or by one discipline alone.

\section{Conclusions}

The aim of the MOTIV think tank was to map what we do and do not know about the drivers of vaccination decision-making, and to look beyond the traditional "one-way" approach to health information. In-depth understanding of complex decision-making processes - through appropriate collaborative research across multiple disciplines - is key to better understanding the drivers and barriers of trust in vaccination, and defining how best to engage publics. This provides a first step towards building a dynamic multidisciplinary research network, in both developed and developing countries, that can synthesize research findings within a coordinated research program, develop interventions, and eventually facilitate increasingly evidence-based vaccination policy.

\section{Acknowledgments}

This article summarizes the discussions held at the MOTIV think tank meeting in London in December 2010, which was supported by Sanofi Pasteur and the London School of Hygiene \& Tropical Medicine and led by Heidi Larson. The authors present these results on behalf of the other MOTIV faculty members: Tim Appenzeller, Nature Journal, London, N1 9XW, UK; Louis Cooper, College of Physicians and Surgeons of Columbia University, New York, NY 10032, USA; Pete Cranston, Independent Consultant, Digital Strategy and Knowledge Management, Oxford OX4 1SU, UK; David Heymann, Infectious Disease Epidemiology, London School of Hygiene and Tropical Medicine, London WC1 7HT, UK; Seth Kalichman, Psychology Department, University of Connecticut, Storrs, CI 06269, USA; Stanley Plotkin, University of Pennsylvania, Doylestown, PA 18902, USA; Claire Topal, Pacific Health Summit, Seattle, WA 98103, USA; Kasisomayajula Viswanath, Department of Society, Human Development and Health, Harvard School of Public Health, Boston, MA, USA; Michael Watson, Vaccination Policy \& Advocacy, Sanofi Pasteur, Lyon 69007, France; Jo Yarwood, Department of Health, London SE1 8UG, UK. The authors thank Communigen Ltd. (Oxford, UK) for their assistance in facilitating and summarizing the workshop. The authors take sole responsibility for the article's content. 


\section{Conflict of Interest}

All authors have completed the Unified Competing Interest form (available on request from the corresponding author) and declare that (1) AT, TA, PC, DH, SK, CM, SP, CT, KV, MW, JY have support from Sanofi Pasteur for the submitted work; JL, HL, and LC have support from The Gates Foundation and London School of Hygiene \& Tropical Medicine for the submitted work; SA has support from the Wellcome Trust for the submitted work; NS is a member of the Imperial Center for Patient Safety and Service Quality, which is funded by the National Institute for Health Research (NIHR), UK and is currently funded by an unrestricted research grant by Sanofi Pasteur and also by the National Institute for Health Research (UK), via the Imperial Patient Safety Translational Research Center; JL has previously been an investigator on a study of pediatric influenza vaccination with part funding from Sanofi Pasteur. The views expressed are those of the authors and not necessarily those of the NHS, the NIHR, the Department of Health, or Sanofi Pasteur. The funders do not have any editorial control over the work reported in this article; (2) HL, SA, TA, LC, PC, DH, SK, CM, SP, CT, $\mathrm{KV}$, JY have no relationships with Sanofi Pasteur that might have an interest in the submitted work in the previous 3 years; AT and MW have a specified relationship with Sanofi Pasteur that might have an interest in the submitted work in the previous 3 years; (3) HL, SA, JL, NS, TA, LC, PC, DH, SK, CM, $\mathrm{SP}, \mathrm{CT}, \mathrm{KV}$, JY declare that their spouses, partners, or children have no financial relationships that may be relevant to the submitted work; AT and MW have a specified relationship with Sanofi Pasteur that might have an interest in the submitted work in the previous 3 years; and (4) HL, SA, JL, NS, TA, LC, PC, DH, SK, CM, SP, CT, KV, JY do not have non-financial interests that may be relevant to the submitted work; AT and MW have specified non-financial interests that may be relevant to the submitted work.

\section{References}

1. Larson, H.J.; Cooper, L.Z.; Eskola, J.; Katz, S.L.; Ratzan, S. Addressing the vaccine confidence gap. Lancet 2011, 378, 526-535.

2. Leask, J. Target the fence-sitters. Nature 2011, 473, 443-445.

3. Wakefield, A.J.; Murch, S.H.; Anthony, A.; Linnell, J.; Casson, D.M.; Malik, M.; Berelowitz, M.; Dhillon, A.P.; Thomson, M.A.; Harvey, P. Ileal-lymphoid-nodular hyperplasia, non-specific colitis, and pervasive developmental disorder in children. Lancet 1998, 351, 637-641.

4. The Editors of The Lancet. Retraction-Ileal-lymphoid-nodular hyperplasia, non-specific colitis, and pervasive developmental disorder in children. Lancet 2010, 375, 445.

5. The National Health Service Information Centre. NHS immunisation statistics England 2008-09. Availeble online: http://www.nursingtimes.net/Journals/1/Files/2009/9/3/NHS_Immunisation_ Statistics_England_2008_09_Bulletin.pdf (accessed on 11 February 2013).

6. Editorial Team. Measles once again endemic in the United Kingdom. Euro Surveillance: Bulletin Europeen sur les Maladies Transmissibles. Eur. Commun. Dis. Bull. 2008, 13, 3.

7. European Centre for Disease Prevention and Control. European monthly measles monitoring (EMMO). Availeble online: http://ecdc.europa.eu/en/publications/Publications/SUR_EMMO_ European-monthly-measles-monitoring-February-2012.pdf (accessed on 11 February 2013). 
8. Yahya, M. Polio Vaccines-Difficult to Swallow. The Story of a Controversy in Northern Nigeria. Availeble online: http://www.ids.ac.uk/publication/polio-vaccines-difficult-to-swallow-the-storyof-a-controversy-in-northern-nigeria (accessed on 11 February 2013).

9. Centers for Disease Control and Prevention. Wild poliovirus type 1 and type 3 importations15 countries, Africa, 2008-2009. MMWR 2009, 58, 357-362.

10. Larson, H.J.; Ghinai, I. Lessons from polio eradication. Nature 2011, 473, 446-447.

11. Brown, K.F.; Kroll, J.S.; Hudson, M.J.; Ramsay, M.; Green, J.; Vincent, C.A.; Fraser, G.; Sevdalis, N. Omission bias and vaccine rejection by parents of healthy children: Implications for the influenza A/H1N1 vaccination program. Vaccine 2010, 28, 4181-4185.

12. Briss, P.A.; Rodewald, L.E.; Hinman, A.R.; Shefer, A.M.; Strikas, R.A.; Bernier, R.R.; Carande-Kulis, V.G.; Yusuf, H.R.; Ndiaye, S.M.; Williams, S.M. Reviews of evidence regarding interventions to improve vaccination coverage in children, adolescents, and adults. The task force on community preventive services. Am. J. Prev. Med. 2000, 18, 97-140.

13. Vannice, K.S.; Salmon, D.A.; Shui, I.; Omer, S.B.; Kissner, J.; Edwards, K.M.; Sparks, R.; Dekker, C.L.; Klein, N.P.; Gust, D.A. Attitudes and beliefs of parents concerned about vaccines: Impact of timing of immunization information. Pediatrics 2011, 127, S120-S126.

14. Cairns, G.; MacDonald, L.; Angus, K.; Walker, L.; Cairns-Haylor, T.; Bowdler, T. Systematic literature review of the evidence for effective national immunisation schedule promotional communications. Available online: http://www.ecdc.europa.eu/en/publications/publications/ literature-review-national-immunisation-schedule-promotional-communications.pdf (accessed on 11 February 2013).

15. Brown, K.F.; Shanley, R.; Cowley, N.A.L.; van Wijgerden, J.; Toff, P.; Falconer, M.; Ramsay, M.; Hudson, M.J.; Green, J.; Vincent, C.A.; et al. Attitudinal and demographic predictors of measles, mumps and rubella (MMR) vaccine acceptance: Development and validation of an evidence-based measurement instrument. Vaccine 2011, 29, 1700-1709. 


\section{Appendix}

Appendix 1. Factors (Drivers and Barriers) Affecting Vaccination Uptake and Sample Research Questions.

\begin{tabular}{|c|c|c|c|}
\hline Domain & Cluster & Potentially influencing factors & Sample research questions \\
\hline \multirow[b]{2}{*}{$\begin{array}{c}\text { Cognition and } \\
\text { decision-making }\end{array}$} & Trust & $\begin{array}{ll}\text { 1. } & \text { Trust in national institutions } \\
\text { 2. } & \text { Trust in healthcare workers } \\
\text { 3. } & \text { Trust in authorities/experts } \\
\text { 4. } & \text { Trust in research } \\
\text { 5. } & \text { Trust in policy } \\
\text { makers/accountability } \\
\text { 6. } \\
\text { 7. } & \text { Trust in media } \\
\text { 8. } & \text { Trust in vaccine industry } \\
\text { 9. } & \text { Trust in vaccines } \\
\text { 10. } & \text { Interpersonal trust } \\
\text { 11. } & \text { Industry-policy maker-researcher } \\
& \text { trust } \\
\text { 12. } & \text { Transparency } \\
\text { 13. } & \text { Competency }\end{array}$ & $\begin{array}{l}\text {-How should trust be measured? } \\
\text { What are the drivers of trust (intellectual, } \\
\text { personalities, environmental-external } \\
\text { physical drivers, etc.)?-Who do } \\
\text { different groups trust? Who are real } \\
\text { influencers? } \\
\text {-Do different publics trust the media } \\
\text { differently? } \\
\text {-What is the trust spectrum for vaccines? } \\
\text {-Who influences different population } \\
\text { segments (e.g., mapping trust networks)? } \\
\text {-What determines trust in a) health } \\
\text { officials and experts; b) healthcare } \\
\text { workers; and c) policy makers? } \\
\text {-How can public confidence in } \\
\text { vaccination be engendered, protected and } \\
\text { measured? }\end{array}$ \\
\hline & $\begin{array}{l}\text { Risk and } \\
\text { perception }\end{array}$ & $\begin{array}{l}\text { 14. Heuristics (e.g., confirmatory } \\
\text { bias, regret bias, omission bias) } \\
\text { 15. Post-hoc rationalisation } \\
\text { 16. Risk-benefit assessments } \\
\text { 17. Scientific/medical literacy } \\
\text { 18. Physical sensations } \\
\text { 19. Perceptions about the faith and } \\
\text { fear of injecting substances } \\
\text { 20. Perceptions regarding vaccine } \\
\text { adverse events, including their } \\
\text { likelihood and severity } \\
\text { 21. Invisible disease (low perception } \\
\text { of risk) }\end{array}$ & $\begin{array}{l}\text {-Which heuristics are most prevalent or } \\
\text { widely used when it comes to vaccine } \\
\text { decision-making? } \\
\text {-How do you change an individual's } \\
\text { norm or reference point? } \\
\text {-How multiple heuristics interact in } \\
\text { vaccine decision-making? } \\
\text { Why are some issues very } \\
\text { vaccine-specific whereas others concern } \\
\text { several vaccines? } \\
\text {-Do actions or thoughts/feelings } \\
\text { come first? } \\
\text { What is the impact of fear? } \\
\text {-Can we create a segmentation of } \\
\text { different decision-making styles } \\
\text { How do people interpret messages } \\
\text { (mental shortcuts, biases, heuristics) and } \\
\text { overestimate risks? } \\
\text {-Do healthcare workers decide differently } \\
\text { for patients vs. themselves? If so, what } \\
\text { influences this? } \\
\text {-Do healthcare workers' perceptions } \\
\text { mirror those seen in public? Are } \\
\text { healthcare workers' perceptions different } \\
\text { from those of the public? } \\
\text {-Why do healthcare workers not accept } \\
\text { vaccines themselves-even if they } \\
\text { recommend them to their patients? } \\
\text { Can we measure "what" and "how" } \\
\text { people understand and remember } \\
\text { (information, experiences)? }\end{array}$ \\
\hline
\end{tabular}


Appendix 1. Cont.

\begin{tabular}{|c|c|c|c|}
\hline Domain & Cluster & Potentially influencing factors & Sample research questions \\
\hline $\begin{array}{c}\text { Cognition and } \\
\text { decision-making }\end{array}$ & Decision context & 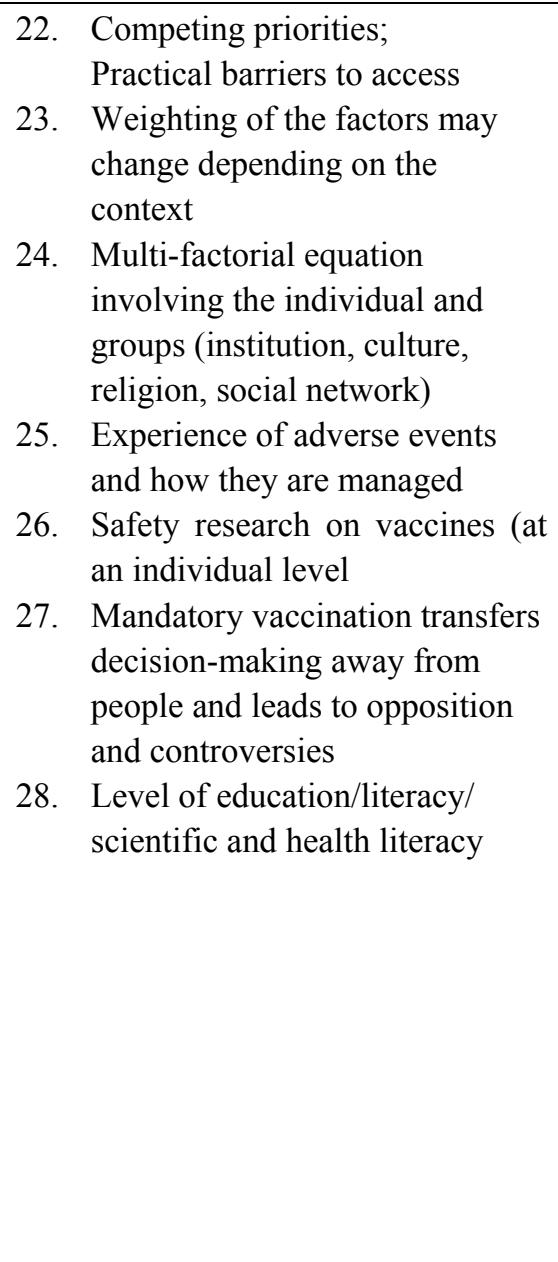 & $\begin{array}{l}\text {-For which segments is having a } \\
\text { vaccine a decision? } \\
\text {-What makes vaccines a lower priority? } \\
\text {-Why are some issues very vaccine- } \\
\text { specific whereas others concern several } \\
\text { vaccines? } \\
\text {-Which public and individual contexts } \\
\text { influence vaccine } \\
\text { decision-making? } \\
\text {-What is the relationship between } \\
\text { decision-making and notions of } \\
\text { climate change? } \\
\text { How can healthcare systems adapt to } \\
\text { different public attitudes (policy } \\
\text { through to implementation)? } \\
\text { Why do some controversies remain } \\
\text { local or specific to one particular } \\
\text { vaccine? } \\
\text { Macro perspectives are needed to link } \\
\text { behavior to the broader context (e.g., } \\
\text { government) within a theoretical } \\
\text { framework } \\
\text { To what extent do vaccine-critical } \\
\text { groups influence decision-making? } \\
\text { Poor literacy leads to low uptake but } \\
\text { good literacy also leads to low uptake. } \\
\text { Can we solve the puzzle? } \\
\text { Who are the policy influencers? }\end{array}$ \\
\hline $\begin{array}{l}\text { Groups and } \\
\text { social norms }\end{array}$ & Groups/grouping & $\begin{array}{ll}\text { 29. } & \text { Social networks } \\
\text { 30. } & \text { Religious groups } \\
\text { 31. } & \text { Groups by education-level } \\
\text { 32. } & \text { Alternative medicine groups } \\
\text { 33. } & \text { Political groups } \\
\text { 34. } & \text { Anti-vaccination groups } \\
\text { 35. } & \text { Family groups/structures } \\
\text { 36. } & \text { Patient groups } \\
\text { 37. } & \text { Consumer groups } \\
\text { 38. } & \text { Professional groups } \\
\text { 39. } & \text { Peer pressure } \\
\text { 40. } & \text { Heterogeneous groups } \\
\text { 41. } & \text { Demographic (socioeconomic) } \\
\text { groups } \\
\text { 42. Influence of alternative } \\
\text { healthcare givers such as } \\
\text { Chinese medicine }\end{array}$ & $\begin{array}{l}\text { What is the role of parental questioning } \\
\text { about health and education and the shift } \\
\text { towards 'intensive' parenting? } \\
\text { Role of peer pressure? } \\
\text { How do memes (a unit of cultural } \\
\text { information transferable from one mind } \\
\text { to another) travel between groups in a } \\
\text { constantly and globally connected } \\
\text { society? } \\
\text { What is the role of culture and religion } \\
\text { on decision-making? } \\
\text { How do a few anti-vaccine individuals } \\
\text { influence the 'swing voters'/vaccine } \\
\text { hesitants? } \\
\text { Understand the heterogeneity of } \\
\text { groups/publics } \\
\text { Role of social pressure and altruism in } \\
\text { decision-making. What are the benefits } \\
\text { to society? }\end{array}$ \\
\hline
\end{tabular}


Appendix 1. Cont.

\begin{tabular}{|c|c|c|c|}
\hline Domain & Cluster & Potentially influencing factors & Sample research questions \\
\hline \multirow[t]{2}{*}{$\begin{array}{l}\text { Groups and } \\
\text { social norms }\end{array}$} & Groups/grouping & & $\begin{array}{l}\text { Define the network of influencers and } \\
\text { the context. What is the best way to } \\
\text { communicate with this network? } \\
\text { Can we develop a new model to measure } \\
\text { and/or assess the level } \\
\text { of influence? } \\
\text { What are the factors that make a family } \\
\text { vaccination strategy (e.g., "cocoon" } \\
\text { strategy in pertussis) } \\
\text { "to protect your family members" } \\
\text { successful or not? } \\
\text { Can we learn lessons from military } \\
\text { strategy about engaging with publics, } \\
\text { especially with respect to parallel access } \\
\text { and trust building and "hearts and } \\
\text { minds" campaigns? } \\
\text { Is there a way to better understand } \\
\text { and/or to classify vaccine-critical } \\
\text { groups? Is there a real/organised } \\
\text { anti-vaccine lobby? }\end{array}$ \\
\hline & Social norms & $\begin{array}{l}\text { 43. Social and cultural norms } \\
\text { 44. Vaccination as a routine/norm }\end{array}$ & $\begin{array}{l}\text {-Which social norms influence } \\
\text { vaccination decisions? } \\
\text {-How can acceptance of safe, effective } \\
\text { vaccines be sustained as a social norm? } \\
\text {-How do different types of protective } \\
\text { norms influence decision-making? }\end{array}$ \\
\hline $\begin{array}{l}\text { Communications } \\
\text { and engagement }\end{array}$ & Sender & 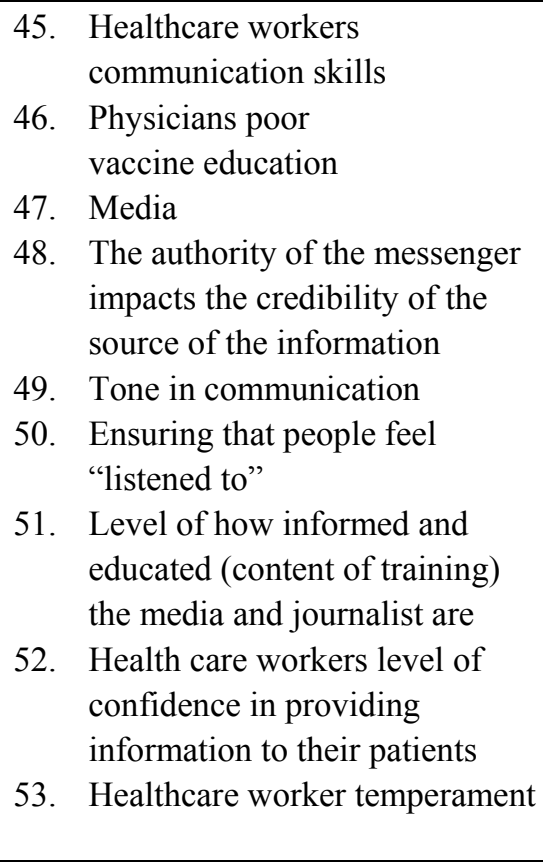 & $\begin{array}{l}\text { How do physicians communicate with } \\
\text { patients? How do patients communicate } \\
\text { with physicians? What are the outcomes } \\
\text { of these interactions? } \\
\text { What is the impact of fear? } \\
\text { How should messages be framed or } \\
\text { constructed? How does the use of } \\
\text { exemplars and narratives apply } \\
\text { to vaccination? } \\
\text { How do ideas travel and how do we } \\
\text { communicate with each other in the } \\
\text { "connected generation"? What does } \\
\text { "constantly connected" mean? } \\
\text { Is Institute of Medicine report on } \\
\text { consumer-provider relationship } \\
\text { regarding vaccines globally relevant? } \\
\text { What are the sources that journalists use } \\
\text { for information? How credible are these } \\
\text { sources? }\end{array}$ \\
\hline
\end{tabular}

(C) 2013 by the authors; licensee MDPI, Basel, Switzerland. This article is an open access article distributed under the terms and conditions of the Creative Commons Attribution license (http://creativecommons.org/licenses/by/3.0/). 